\title{
Plasma transport along discrete auroral arcs and its contribution to the ionospheric plasma convection
}

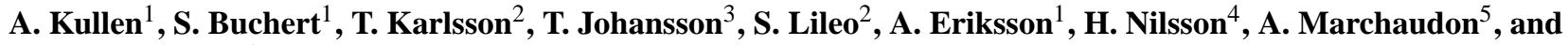 \\ A. N. Fazakerley ${ }^{6}$ \\ ${ }^{1}$ Swedish Institute of Space Physics, Uppsala Division, Sweden \\ ${ }^{2}$ Space and Plasma Physics, School of Electrical Engineering, Royal Institute of Technology, Stockholm, Sweden \\ ${ }^{3}$ Laboratory for Atmosphere and Space Physics, University of Colorado, Boulder, USA \\ ${ }^{4}$ Swedish Institute of Space Physics, Kiruna Division, Sweden \\ ${ }^{5}$ Laboratoire de Physique et Chimie de l'Environnement, CNRS, Orléans, France \\ ${ }^{6}$ Mullard Space Science Laboratory, University College London, Surrey, UK
}

Received: 17 April 2008 - Revised: 14 August 2008 - Accepted: 27 August 2008 - Published: 21 October 2008

\begin{abstract}
The role of intense high-altitude electric field (Efield) peaks for large-scale plasma convection is investigated with the help of Cluster E-field, B-field and density data. The study covers 32 E-field events between 4 and $7 R_{E}$ geocentric distance, with E-field magnitudes in the range 500$1000 \mathrm{mV} / \mathrm{m}$ when mapped to ionospheric altitude. We focus on E-field structures above the ionosphere that are typically coupled to discrete auroral arcs and their return current region. Connected to such E-field peaks are rapid plasma flows directed along the discrete arcs in opposite directions on each side of the arc.
\end{abstract}

Nearly all the E-field events occur during active times. A strong dependence on different substorm phases is found: a majority of intense E-field events appearing during substorm expansion or maximum phase are located on the nightside oval, while most recovery events occur on the dusk-todayside part of the oval. For most expansion and maximum phase cases, the average background plasma flow is in the sunward direction. For a majority of recovery events, the flow is in the anti-sunward direction.

The net plasma flux connected to a strong E-field peak is in two thirds of the cases in the same direction as the background plasma flow. However, in only one third of the cases the strong flux caused by an E-field peak makes an important contribution to the plasma transport within the boundary plasma sheet. For a majority of events, the area covered by rapid plasma flows above discrete arcs is too small to have

Correspondence to: A. Kullen

(kullen@irfu.se) an effect on the global convection. This questions the role of discrete auroral arcs as major driver of plasma convection.

Keywords. Ionosphere (Auroral ionosphere; Electric fields and currents; Planetary ionospheres)

\section{Introduction}

The auroral oval consists of two types of aurora: bright discrete auroral arcs, and diffuse aurora. The distribution of the auroral precipitation varies strongly with latitude, magnetic local time (MLT) and geomagnetic activity.

1.1 The spatial distribution of discrete auroral arcs and diffuse aurora

The distribution of different plasma regimes above the auroral ionosphere and their magnetospheric source regions is a matter of large debate in the research community. Here, a brief overview over the different auroral regions and their origin is given. For a detailed debate about that topic, we refer to Newell et al. (1996a) and Feldstein et al. (2001).

At the nightside, diffuse aurora is mainly concentrated to the equatorward oval region, which maps to the quasi-dipolar near-Earth part of the plasma sheet, defined by Winningham et al. (1975) as the central plasma sheet (CPS). Diffuse aurora is caused by spatially unstructured hot electrons in the $\mathrm{keV}$ range. Discrete auroral arcs appear typically poleward of the diffuse auroral region and map to the plasma sheet poleward (tailward) of the stable trapping boundary of $35 \mathrm{keV}$ electrons (Weiss et al., 1992, and references therein) and its

Published by Copernicus Publications on behalf of the European Geosciences Union. 
boundary layer (PSBL) (Yahnin et al., 1997). The oval of discrete arcs coincides roughly with the region of stretched magnetic field lines (Yahnin et al., 1997), defined by Winningham et al. (1975) as the boundary plasma sheet (BPS). Discrete arcs are caused by precipitating electrons that have been accelerated to energies of several $\mathrm{keV}$.

The auroral precipitation pattern at the dawnside and duskside oval deviates from the nightside distribution. Due to curvature and gradient drifts, earthward convecting electrons move dawnward when having reached the inner magnetosphere. Hence, the typically broad dawnside oval region contains mainly diffuse aurora (e.g. Hamrin et al., 2005) while on the duskside the region of diffuse aurora is limited to a few degrees latitude (Gérard et al., 2004). To maintain current continuity at the duskside oval, the lack of electrons is compensated by electron acceleration which explains the high occurrence frequency of discrete arcs in this oval sector (Newell et al., 1996b; Hamrin et al., 2005). At the dawnside, discrete arcs may occur as well. However, they are much less frequent (Newell et al., 1996b), have lower energies (Feldstein et al., 2001) and often appear in multiple sheets at the poleward part of the oval (Elphinstone et al., 1990).

\subsection{Auroral distribution during the substorm cycle}

The auroral distribution is further complicated by the dynamic changes during substorm cycles. While the equatorward part of the nightside oval (the region of diffuse aurora) remains nearly unchanged during a substorm, the more poleward region (the oval of discrete arcs) changes considerably between quiet and active times (Winningham et al., 1975). The start of an auroral substorm is preceded by a growth phase during which the entire auroral oval (including the diffuse auroral region) expands towards lower latitudes (McPherron, 1972). Substorm onset starts at the most equatorward discrete arc. The developing auroral surge expands in poleward and westward direction. The substorm expansion phase is dominated by dynamic displays of bright, discrete auroral arcs. When maximal substorm expansion is reached, even auroral regions near the poleward oval boundary are activated (Lyons et al., 1999).

The recovery phase is not merely a simple return to the ground state. Especially when IMF $B_{z}$ has turned northward during the substorm, the oval becomes very broad and remains active throughout the entire recovery phase. For such solar wind conditions, often, the region between poleward and equatorward oval boundary erodes before the still active poleward oval boundary finally fades as well (Kullen and Karlsson, 2004). During this transition, a so-called double oval structure emerges (Elphinstone et al., 1995). The recovery process during northward IMF is poorly understood.

\subsection{Plasma convection and auroral precipitation pattern}

During southward IMF a two-cell convection pattern with an anti-sunward flow direction in the polar cap and sunward plasma flow along the auroral oval is commonly observed. It is connected to the tailward solar wind flow above the polar cap and the sunward plasma convection in the magnetotail plasma sheet, respectively (Dungey, 1961). This two cell-pattern prevails even throughout a substorm cycle, but is overlaid by the substorm current wedge. In the early recovery phase, the convection pattern becomes more complicated, but a two-cell pattern can be discerned again at the end of the recovery (Kamide et al., 1996). During northward IMF, highlatitude lobe reconnection replaces the dayside-nightside reconnection circuit, and the convection pattern changes drastically with one up to several cells appearing inside the polar cap (Weimer, 1995). In addition to merging cells, during positive IMF $B_{z}$ conditions there exist (low-latitude) viscous cells lying completely on closed field lines and (highlatitude) lobe cells that are completely on open field lines (Burch et al., 1985).

It is often assumed that the convection reversal, auroral oval, and open-closed field line boundaries overlap. However, the convection reversal boundary may lie up to one degree (less during southward IMF) equatorward of the openclosed field line boundary (Sotirelis et al., 2005) which means, anti-sunward plasma flow can be observed even on closed field lines. Observations of anti-sunward flow on the dayside part of the high-latitude oval region are commonly explained by its topological connection to the low-latitude boundary layer along the magnetotail flanks (LLBL), as the outer part of the LLBL is known to lie on anti-sunward convecting plasma. This refers to the soft small-scale luminosity region along the most poleward part of the dawnside oval (Newell et al., 1991; Woch and Lundin, 1993) and to the morning and afternoon oval regions at times when the oval becomes tear-drop shaped during northward IMF (Murphree et al., 1982). Occasionally occurring rapid anti-sunward flows near the duskside oval boundary, but poleward of the convection reversal have been suggested to originate in the distant tail reconnection region (Burke et al., 1994).

\subsection{Possible connection between discrete arcs and plasma convection}

Field-aligned electric fields connected to quasi-static (often U-shaped) potential structures above the ionosphere play a dominant role in the acceleration mechanism of discrete auroral arcs (Carlqvist and Boström, 1970; Mozer et al., 1980). Alfvén wave acceleration is another possible driver of discrete arcs. However, signs of Alfvén wave activity are typically found above arcs near the polar cap boundary (Keiling et al., 2001; Schriver et al., 2003).

In the present study we focus on quasi-static electric field (E-field) structures appearing within the BPS. As shown by 
Johansson et al. (2006), quasi-static auroral E-field structures are closely related to plasma boundaries. It is generally believed that plasma shear flows at magnetospheric boundaries within a highly conductive plasma environment lead to magnetic stress that causes field-aligned currents (FACs). The ionosphere acts as a load for the current circuit, and energy is released via Joule heating and electron precipitation. To maintain current continuity, the number of electrons in the loss cone is enhanced by field-parallel E-fields above the high-latitude ionosphere (Knight, 1973). Due to the fieldparallel E-field, the ionosphere becomes locally decoupled from the magnetosphere. On the ionospheric side, the potential drop is connected to the acceleration of precipitating electrons causing discrete auroral arcs. On the magnetospheric side, strong east-west aligned shear flows appear on both sides of the arc.

The connection of strong E-fields with discrete auroral arcs and their return current region has been studied extensively (e.g. Marklund, 1984; Karlsson and Marklund, 1996) while the connection between the acceleration region and magnetospheric source region is less explored. Assuming that the topology of the FAC source region strongly influences the auroral region and vice versa, (Haerendel, 2000, 2002) suggested that the occurrence of locally confined FAC sheets in the auroral region (resulting in multiple discrete arcs at the ionospheric end) is connected to a filamentation of the plasma sheet. Haerendel (2000) demonstrated by a simple calculation that a plasma sheet filamentation is energetically better than a smooth plasma sheet boundary, as the energy conversion in the connected discrete auroral arcs leads to an enhanced energy release from the hot magnetospheric plasma. The locally enhanced plasma flows above discrete arcs help to remove magnetospheric stress from the source region. Thus, discrete arcs serve as "auroral pressure valves" (Haerendel, 1992). According to Haerendel $(1992,2000)$, the east-west extension of auroral arcs indicates a connection with the global convection system. Especially during substorm expansion with strong earthward plasma flows in the tail, discrete arcs help to release pressure and energy in a more sufficient way. Assuming a U-shaped potential drop above discrete arcs, plasma flows on each side of the arc cancel. Thus, Haerendel (2000) concluded that the overall plasma convection will not be enhanced by discrete arcs, only the energy conversion rate. However, observations by Johansson et al. (2007) of a preferred occurrence of intense E-field events at density boundaries and their often non-bipolar shape indicate that rapid flows along discrete arcs (and their return currents) lead to a net plasma flux. Due to the high velocities of these flows, the net flux above arcs could play an important role for the total plasma transport from the nightside to the dayside. A possible contribution of rapid plasma flows to the large-scale plasma convection has not yet been studied observationally.

\subsection{Goal of the study}

In this study, we want to investigate the role of discrete auroral arcs for the large-scale plasma convection by analyzing Cluster E-field and density measurements above the ionosphere. The importance of strong plasma flows above discrete arcs (and connected return current regions) for the large-scale plasma convection is examined by comparing the net plasma transport connected to intense E-field peaks with the background plasma transport within the boundary plasma sheet region.

\section{Data selection}

The events used in this work are taken from a statistical study of intense E-fields by Johansson et al. (2006), based on Efield measurements from the EFW instruments onboard the Cluster satellites (Gustavsson et al., 1997). In their study, the E-field is mapped along the geomagnetic field lines to $100 \mathrm{~km}$ height by using the dipole field approximation, to be able to compare measurements taken at different altitudes. Johansson et al.'s (2006) dataset contains all intense E-field events appearing between January 2001 and September 2003 at geocentric distances between 4 and $7 R_{E}$ with mapped Efield magnitudes in the range of $500-1000 \mathrm{mV} / \mathrm{m}$ that show clear bipolar or monopolar quasi-static E-field structures. The latter requirement has been fulfilled with help of manual inspection of the E-field data. Only the strongest E-field peak per oval passage is regarded. Events that show cusp signatures have been ignored in their study. This concerns a few E-field peaks appearing near noon. The study of Johansson et al. (2006) also contains a few well-defined E-field peak events with magnitudes below $500 \mathrm{mV} / \mathrm{m}$. In the present study, these cases have been excluded. Note, that several of the events analyzed in Johansson et al. (2006) have been investigated in detail within other contexts by Johansson et al. (2004), Figueiredo et al. (2005), and Marklund et al. (2007). The dataset presented in Johansson et al. (2006) is a subset from the dataset used in the large statistical studies by (Johansson et al., 2005, 2007) where all E-field events above $150 \mathrm{mV} / \mathrm{m}$ have been covered. Thus, the results from these studies are directly applicable to our work.

As we are analyzing the plasma flux, only those events from Johansson et al. (2006) are taken into account where density data from CIS (Reme et al., 1997) and/or spacecraft potential measurements are available. A further requirement is a continuous data coverage of at least $30 \mathrm{~min}$ around the peak, as we compare the plasma transport connected to intense E-fields with the background plasma flux surrounding the E-field peak. This reduces the number of oval passages where at least one satellite registers a peak above $500 \mathrm{mV} / \mathrm{m}$ to 24 passages. Only data from spacecrafts 1,3 and 4 are taken into account, as spacecraft 2 data does not provide CIS data. In contrast to Johansson et al. (2006), we count E-field 
peaks measurements from different Cluster satellites during the same passage as separate events only in case of a satellite separation by more than 15 min (6 of 8 such passages have separation times of 20-70 min). Auroral and E-field structures have changed considerably during that time span. Counting in this way, the dataset contains altogether 32 separate E-field peak events.

Electron data from the PEACE instrument on the Cluster spacecrafts (Johnstone et al., 1997) are used to locate the different plasma domains. As could be expected, all studied E-field peak events appear within the highly structured region between polar cap and CPS. Following the definition of Winningham et al. (1975) we refer to this region as the BPS. We do not intend to make a further distinction between subdomains within the BPS, as it is a matter of debate whether the BPS is topologically connected to the PSBL or the tailward part of the plasma sheet (see e.g. Newell et al., 1996a, and references therein) and is not in the main focus of this paper.

For an examination of the solar wind conditions during the E-field peak events IMF data from the OMNIWeb (http:// omniweb.gsfc.nasa.gov) is used. The dataset consists of solar wind measurements from the solar wind monitor which is closest to the Earth bow shock. The data are propagated in time to correspond the solar wind conditions at the Earth bow shock.

For the identification of substorm activity, $A_{E}$ quicklook plots are used (available at http://swdcwww.kugi.kyoto-u.ac. jp/aedir/index.html) containing unchecked data, where not always data from all stations are available. Still, the quicklook plots give a good estimate of existing substorm activity. As we are interested in the average change of the $A_{E}$-value over a time span of $30 \mathrm{~min}$, small or short-time deviations from the real $A_{E}$ value do not affect the results.

\section{Data analysis}

To calculate the local particle flux $f=n \times v=n \times \frac{(\boldsymbol{E} \times \boldsymbol{B})}{B^{2}}$ perpendicular to the magnetic field, we need the plasma density $n$ which we derive both from CIS ion measurements, and from the EFW spacecraft potential $V_{p s}$. In a first step, the total density is calculated by taking the sum of the $\mathrm{H}^{+}, \mathrm{O}^{+}$, $\mathrm{He}^{+}$, and $\mathrm{He}^{++}$density moments, as measured by the CISCODIF detectors. This method works well as long as the spacecraft potential (in V) is lower than the typical ion energy (in eV), so that the plasma ions can reach the CIS detectors on the spacecraft (usually, CIS CODIF has a low energy limit of $10 \mathrm{eV}$ ). However, as the spacecraft potential varies oppositely to the plasma density (Escoubet et al., 1997; Pedersen et al., 2008), tenuous plasmas can lead to spacecraft potentials so high that only a small fraction of the ions can reach the spacecraft and its ion detectors, causing a severe underestimate of the plasma density. To avoid erroneous density estimates from CIS, we compare the CIS measurements with an estimate of the spacecraft potential itself as a density measure. More precisely, we derive the density from the spacecraft potential by using the voltage $V_{p s}$ measured by the EFW instrument between the probes and the spacecraft. This quantity is related to the plasma density by a sum of two exponentials (Escoubet et al., 1997; Pedersen et al., 2008). Here, we simplify to $n=a \times 10^{\frac{V p s-b}{c}}$, where $b$ and $c$ are determined from a reference dataset of density and corresponding $V_{p s}$ values. The value of $a$ is fitted by comparison of the two derived densities in those regions where the spacecraft potential is sufficiently low for CIS to detect the full plasma density. The fitting has been done separately for each event and for each satellite, as long term and daily variations of the solar UV spectrum (Pedersen et al., 2008) as well as peculiarities on individual spaceraft (e.g. differences in current emitted by the EDI instrument, particularly notable for spacecraft 3 that is used here in six cases) lead to significant variations of $a$. For seven events, the spacecraft potential data are ignored, as in these cases the density determination becomes more complicated because of an artificial spacecraft potential control by ASPOC (Torkar et al., 2001).

As we look at the local values of E-field, density and flux transport at Clusters altitude (not their mapped values), a quantitative comparison of the net plasma transport between different events is not possible due to the height-dependence of the studied parameters. However, analyzing each Cluster passage separately, the height-dependence can be neglected due to the small changes in geocentric distance (in average $0.37 R_{E}$ ) within the 30 min Cluster passages above the highlatitude oval that are studied in this work. A height difference of $0.37 R_{E}$ corresponds to only $1.4 \%$ of the entire field line length, considering the shortest possible length of field lines emerging at $71.4^{\circ}$ corrected geomagnetic latitude (average location of the analyzed E-peaks) is $25.1 R_{E}$ (dipole configuration), thus the density change due to Clusters changed position should be negligible. Calculations show that the value of the E-field mapping factor does not change more than 0.5$1 \%$ due to the varying Cluster location within the studied time span.

For each event, plots are produced that contain information about electron energy, E-field, density, and particle flux of one Cluster passage through the poleward part of the BPS. An example of such a summary plot is shown in Fig. 1. It contains an intense E-field event that appeared 15 April 2002 along the duskside oval of the Southern Hemisphere. The first three rows show PEACE electron energy-time spectrograms at pitch angles 0,90 , and 180 degrees. The fourth row shows the orientation of the sheet orthogonal to the maximal E-field gradient, as derived from minimum variance analysis of the E-field. An angle of zero degrees corresponds to an east-west aligned sheet, which is the expected orientation of oval-aligned discrete arcs. The fifth row shows the two E-field components in the ionospheric plane, measured by the EFW-instrument. The red and blue colored curves 


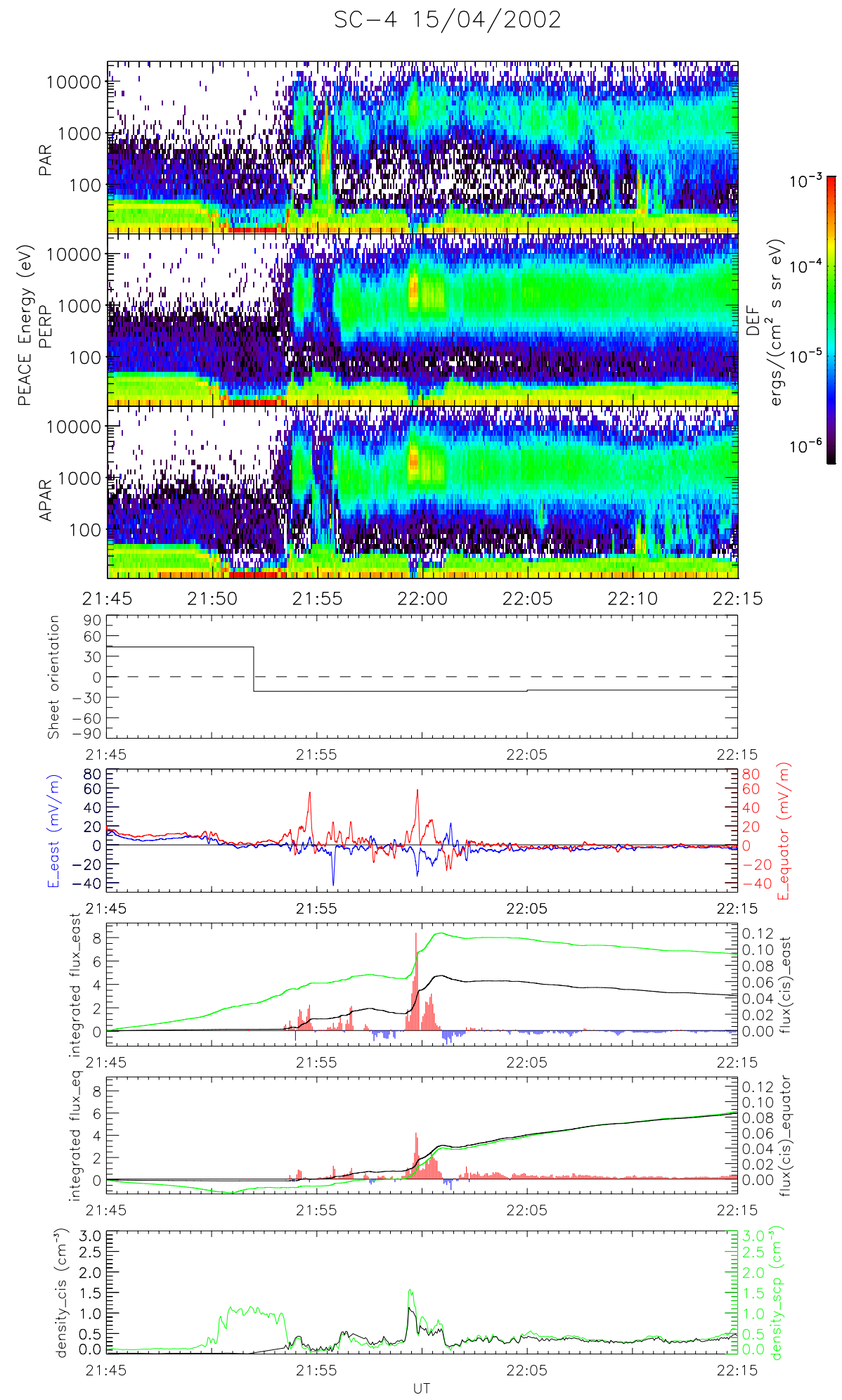

Fig. 1. Measurements by Cluster spacecraft 4 from a southern auroral oval crossing on 15 April 2002. The first three panels are electron energy-time spectrograms, displaying the energy flux in parallel, perpendicular and anti-parallel to the B-field. Panel 4 shows the direction of the sheet orthogonal to the strongest E-field variation. Panel 4 shows the eastward (blue) and equatorward (red) components of the E-field. Panels 5 and 6 show the plasma flux, calculated from CIS density data. The black (green) curve is the integrated flux, using CIS density measurements (density derived from spacecraft potential). The last panel shows the CIS density measurements (black), and the density derived from the spacecraft potential (green). 
correspond to equatorward and eastward E-field components. Rows 6 and 7 show the plasma flux components in eastward and equatorward direction, respectively. Here, only the flux calculation with CIS density data is shown. Overlaid on that plot are curves of the integrated flux, derived from CIS measurements (black curve) and spacecraft potential (green curve). The integration is done over the entire downloaded area starting at highest latitudes. The last row shows the density derived from the spacecraft potential (green) and CIS density data (black). Figure 2 contains data from an E-field peak event occurring 27 April 2002. It is done in the same way as Fig. 1.

In Fig. 1, the green and black density curves (last row) deviate strongly from each other between 21:50-21:54 UT. A high density of ions at too low energies to be detected by CIS is inferred from the $V_{p s}$ density estimate mainly in a small region poleward of the polar cap boundary. Such cold ion outflows (Moore et al., 1997) are seen in half of the cases, most of these in connection with a clear particle cutoff towards the polar cap, as observed from PEACE electron data. However, this has an only small influence on the flux calculation, as in this region the E-field strength drops to values near zero.

In plasma regimes with strong fluxes of high-energetic electrons above $10 \mathrm{keV}$, such as the CPS, or large parts of the nightside oval during substorm expansion, CIS and spacecraft potential data deviate systematically due to the much increased electron energies compared to in the regions where the density- $V_{p s}$ calibration has been done (Escoubet et al., 1997). An example can be seen in the density data of Fig. 2 between 19:57-20:00 UT. Our dataset contains seven such events. As all intense E-field events occur poleward of the high-energetic electron region, this does not affect our results either. In the plasma region surrounding the intense E-field events, CIS density, and density derived from the spacecraft potential measurements, generally show time series of similar shape, allowing a density calibration of the density data derived from the spacecraft potential.

Looking at the E-field data in Fig. 1, a nearly homogenous E-field of about $150 \mathrm{mV} / \mathrm{m}$ is seen inside the polar cap between 21:45 and 21:50 UT. Such a field appears in several of our events inside the polar cap. This E-field is an "artificial" field that does not exist in the surrounding plasma, but is created as a very large wake forms behind the spacecraft in regions of very cold and tenuous plasma flow (Eriksson et al., 2006; Engwall et al., 2006), like, e.g. in the polar wind.

\section{Results}

\subsection{The spatial distribution of strong E-field events}

In Fig. 3, the locations of all intense E-field events are shown in polar coordinates. Longitude and latitude are given in magnetic local time (MLT) and corrected geomagnetic latitude (CGLat), respectively. The paths from all Clus- ter satellites are plotted that contain an E-field peak above $500 \mathrm{mV} / \mathrm{m}$, even those paths where the satellite separation is less than $5 \mathrm{~min}$ (in the present study not counted as separate events), resulting in nearly identical satellite paths in the plot for these events. Figure 3 shows only that part of the $30 \mathrm{~min}$ long satellite path that lies inside the auroral oval. The poleward end of the lines corresponds to the poleward oval boundary, identified from PEACE electron data. For example, for the E-field peak event of Fig. 1, only the part of the satellite path between 21:53 and 22:15 is plotted.

In 3 cases, the poleward limit of the downloaded region is close to, but does not cover the poleward oval boundary. The satellite path closest to 90 degrees covers a transpolar arc. The red and blue colors correspond to an average plasma flow direction within the plotted region in a sunward or anti-sunward direction, respectively. For the afternoon (prenoon) cases, we define a westward (eastward) flow direction as "sunward". For the premidnight (postmidnight) cases, a sunward flow means all flow directions between entirely poleward and entirely westward (eastward).

Figure 3 shows that the events are not evenly distributed over all MLT. Most appear in the nightside oval sector, with a maximal occurrence in the pre-midnight sector. Less events are found on the dayside. There is a clear dawnduskward asymmetry with far more events on the dusk side than on the dawn side, and a total lack of events between 04:00 and 07:00 MLT. The lack of events between 11:00 and 02:00 MLT is caused by the removal of E-field peak events with cusp signatures. Looking at the average plasma flow direction of each satellite passage, we get the unexpected result that over half of the E-field peaks are embedded in a region of anti-sunward plasma flow. Anti-sunward flows appear over all MLT except at dawn while the sunward cases are concentrated to the nightside oval.

\subsection{Sunward and anti-sunward flow connected to substorm phases}

A look at the $A_{E}$ index shows that 30 of the 32 intense E-field events appear during magnetically disturbed times $\left(A_{E}>200 \mathrm{nT}\right)$. It is found that the background plasma flow direction and spatial distribution of the events is connected to different substorm phases. This is shown in Fig. 4. The events are sorted into three different substorm categories: substorm expansion or peak substorms (left plot), small substorms or steady magnetospheric convection (SMC) events (middle plot), and recovery phase or quiet time events (right plot). The substorm phases are identified from $A_{E}$ quicklook plots. In the left plots only those events are shown where a clear $A_{E}$ increase or fluctuations around maximal $A_{E}$ values are seen. The right plot contains all events with a clear $A_{E}$ decrease. The middle plot contains all events with so small or short-time $A_{E}$ variations that no clear substorm phase could be discerned during the $30 \mathrm{~min}$ time span, we consider. 
SC-4 27/04/2002
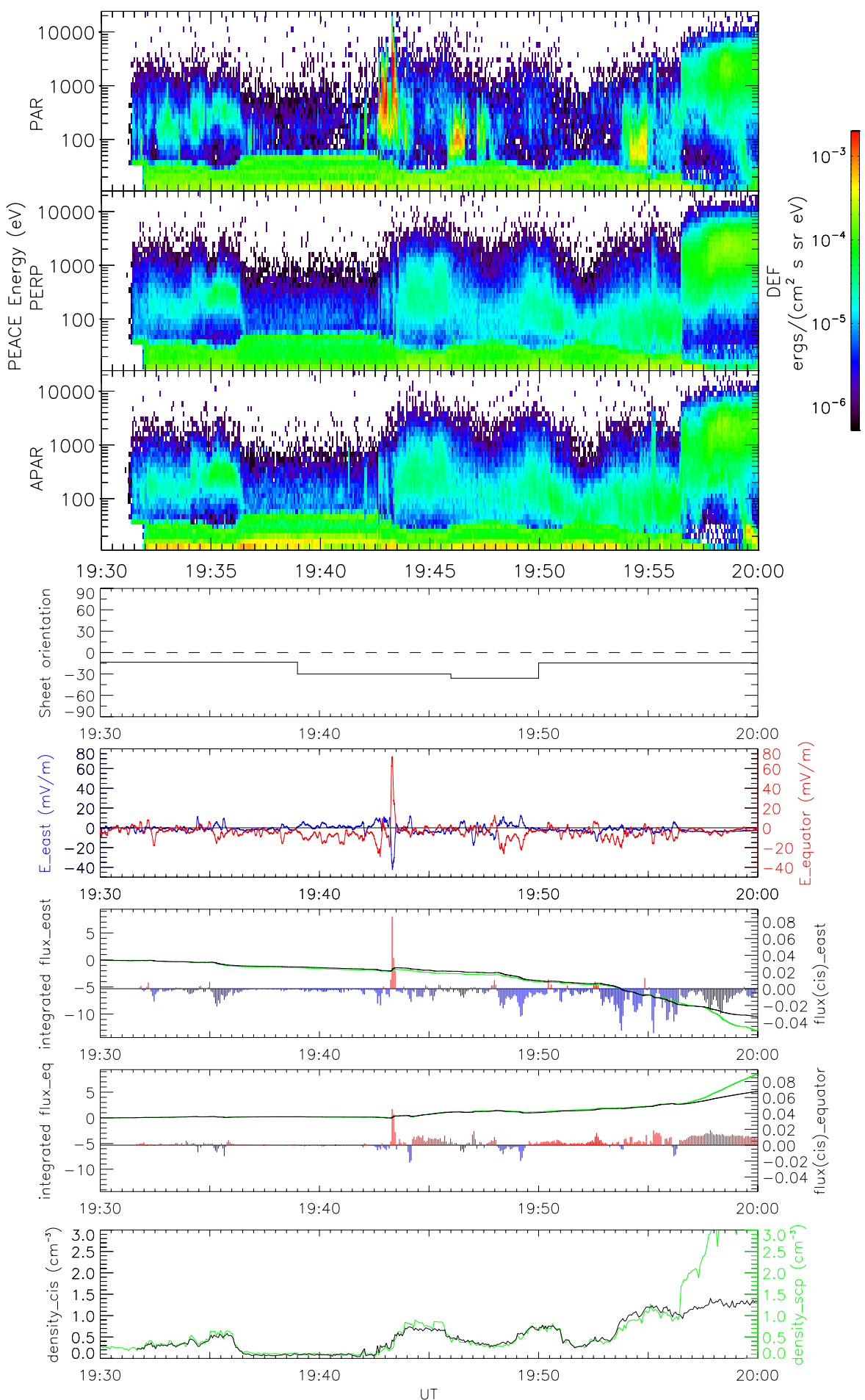

Fig. 2. Measurements by Cluster spacecraft 4 from a southern auroral oval crossing on 27 April 2002. The panels are in the same format as Fig. 1. 


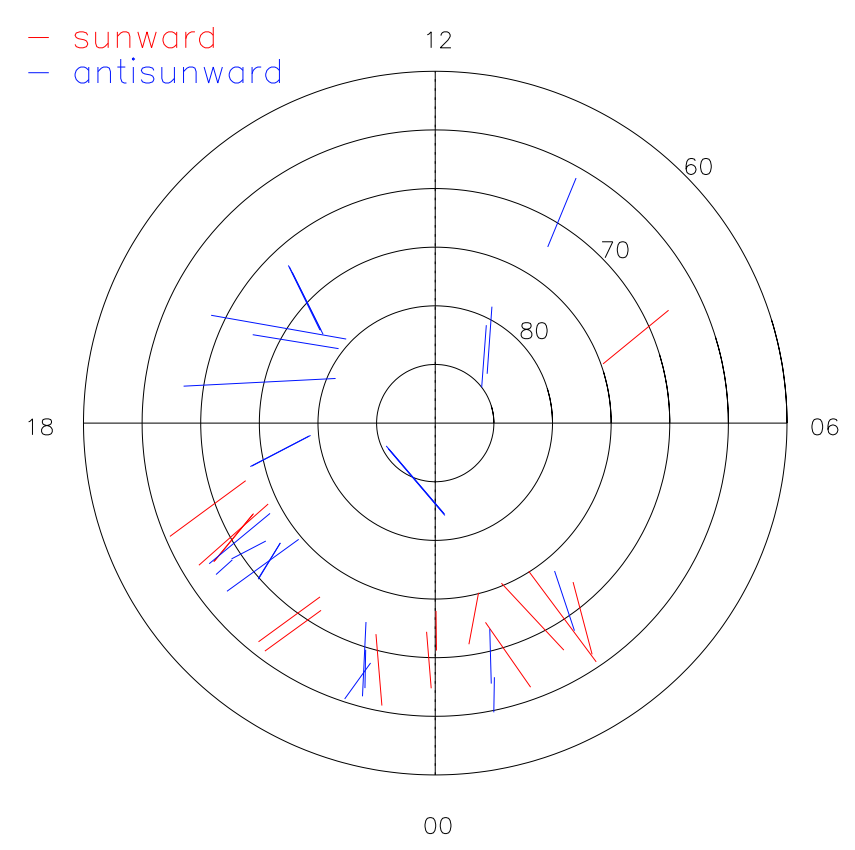

Fig. 3. A polar plot of all Cluster oval crossings during 20012003 that contain intense E-field events above $500 \mathrm{mV} / \mathrm{m}$. The red and blue lines correspond to poleward oval crossings with average plasma flow direction in sunward and in anti-sunward direction, respectively. The poleward end of each line corresponds to the polar cap boundary.

The two quiet time events both appear after $2 \mathrm{~h}$ of very low $A_{E}$ values. The expansion/peak substorm events belong to large substorms. All except one event (with $400 \mathrm{nT}$ maximum $A_{E}$ ) appear during substorms with maximum $A_{E}$ values of $500 \mathrm{nT}$ or larger. Even the recovery events belong to strong substorms. For six of nine events, $A_{E}$ values are larger than $500 \mathrm{nT}$ within the last $1.5 \mathrm{~h}$ before the peak occurs. The remaining events (shown in the middle plot) all appear during periods of weakly enhanced geomagnetic activity. The maximal $A_{E}$ values vary between 200 and $500 \mathrm{nT}$, when looking at a time period of $1.5 \mathrm{~h}$ before the E-field peak appears. Two events show typical SMC signatures with many hours of intermediate substorm activity without clear expansion or recovery (Sergeev et al., 1996), the remaining events are small substorms of 20 to 60 min duration. Even the small substorms appear during many hours of continuous substorm activity, i.e. none of the small substorms are isolated substorms within a quiet time period. As the Cluster satellites need about 30-60 min to cross the entire BPS, no clear substorm phase could be determined for these cases.

As could be expected, nearly all expansion and peak substorm events appear along the nightside oval. For small substorm/SMC activity, most of the intense E-field events are shifted to the pre-midnight region. They appear at slightly higher latitudes than those during large expansion phases, as the oval size decreases for smaller substorms and during
SMCs (Kullen and Karlsson, 2004). The two events at highest latitudes are the two quiet time events, one of them is an E-field peak at the boundary of the above mentioned transpolar arc, the other an E-field peak near the prenoon oval boundary which is understandable due to the oval contraction during quiet times (Makita et al., 1988). Unexpectedly, most of the recovery E-field peaks appear at high latitudes in the dusk-to-noon oval sector.

Looking at the average flow direction in Fig. 4, a clear pattern is seen. Most expansion phase E-field peaks are embedded within a region of sunward flow, while nearly all recovery phase events, and the two quiet time events lie on auroral field line regimes with anti-sunward flow. For small substorms and SMC events, no preferable flow direction is found.

\subsection{The dependence on IMF conditions}

An examination of the solar wind conditions during the intense E-field events reveals a connection between the substorm phases during which the events occur and the IMF $B_{z}$ component. Table 1 summarizes the IMF $B_{z}$ conditions (in GSM coordinates) for all E-field peak events, sorted into the same substorm categories as in Fig. 4: substorm expansion or peak substorm events, small substorms or SMC events, and substorm recovery or quiet time events. The number of events is given, where the IMF is predominantly northward or southward during the hour before the E-field peak event, and where the E-field peak appears in connection with a clear IMF Bz sign change (IMF $B_{z}$ northward or southward turning \pm 5 min around E-field peak appearance).

As could be expected, nearly all substorm expansion and peak substorm events appear after at least one hour of predominantly southward IMF. Even small substorms and SMC events appear in a majority in connection with southward IMF. However, IMF $B_{z}$ is much more varying in these cases. Interestingly, most events of the last substorm category appear after predominantly northward IMF. The connection between northward IMF and the two quiet time events is expected. More surprising is that even most recovery events appear during northward IMF conditions although substorm recovery is not in general connected to that IMF direction. Typically, a substorm, including its recovery takes place during a prolonged period of southward IMF (Hsu and McPherron, 2003).

\subsection{Examples of intense E-field events}

We now turn to the main question of this paper: How much do the rapid plasma flows, caused by the local decoupling between ionosphere and magnetosphere due to large potential drops influence the global plasma convection? To answer that question, the particle flux is integrated over a $30 \mathrm{~min}$ long Cluster passage covering the entire (afternoon cases), or the poleward part of the BPS (nigthside expansion cases). The 

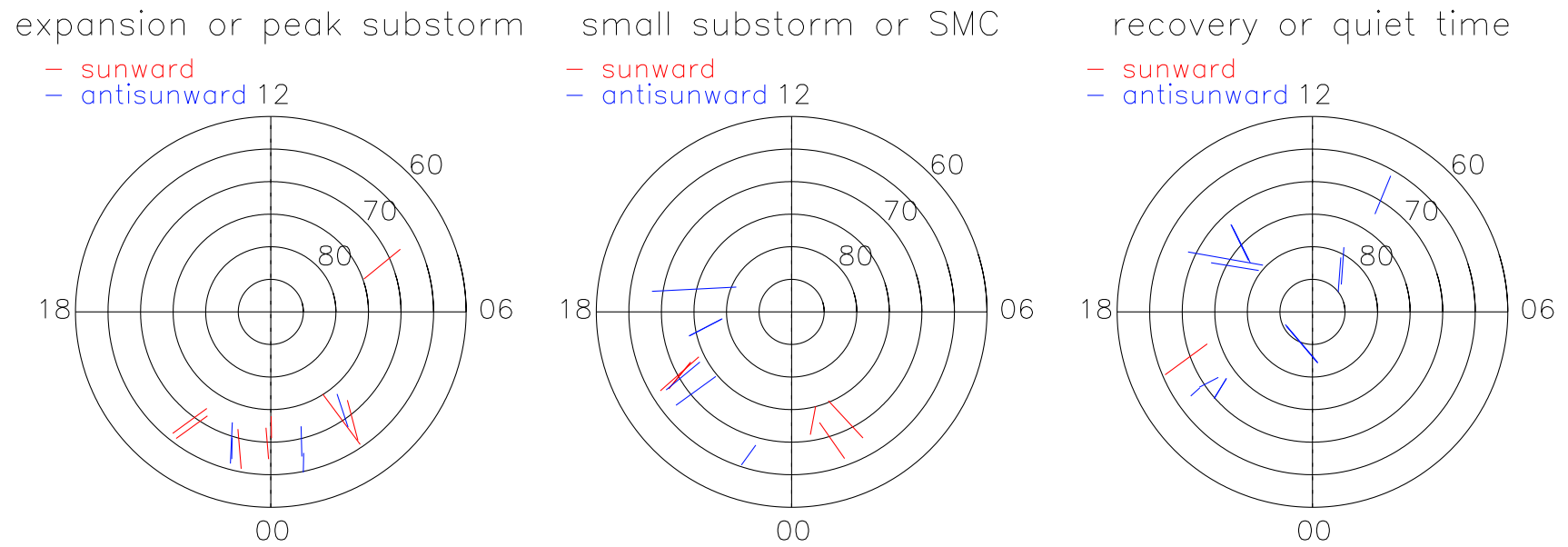

Fig. 4. The distribution of intense electric field events sorted according to different substorm phases: The left plot shows all poleward oval crossings where an intense E-field event appears during substorm expansion or peak substorm phase. The middle plot contains all events during small substorms or SMC events. The right plot contains all substorm recovery and quiet time cases. The red and blue colors correspond to an average plasma flow direction in sunward and in anti-sunward direction, respectively.

Table 1. IMF $B_{z}$ conditions during the hour before the E-peak occurrence.

\begin{tabular}{lcccc}
\hline IMF $B_{z}(\mathrm{GSM})$ & $\begin{array}{c}\text { southturn } \\
\text { at E-peak }\end{array}$ & $\begin{array}{c}\text { southward } \\
\text { IMF }\end{array}$ & $\begin{array}{c}\text { northturn } \\
\text { at E-peak }\end{array}$ & $\begin{array}{c}\text { northward } \\
\text { IMF }\end{array}$ \\
\hline Substorm expansion events & 0 & 11 & 1 & 1 \\
Small substorms / SMC events & 2 & 5 & 0 & 1 \\
Substorm recovery events & 2 & 1 & 0 & 8 \\
\hline
\end{tabular}

direction and magnitude of the E-field peak contribution to the average plasma transport within that region is recorded.

Figure 1 shows an example where one of two very intense E-field peaks leads to a large plasma flux, as compared to the background flux within the BPS regime. This event occurred near the polar cap boundary at the dusk oval side (around 21:00 MLT) of the Southern Hemisphere during the recovery phase of a substorm. One of the nearly monopolar Efield peaks appears in connection with a density maximum (at 21:59:30 UT). For this E-field peak the plasma flux is strongly enhanced over a broad region (21:59 and 22:01 UT). The shape of the E-field peak and the density enhancement over the entire width of the E-field peak contribute to the high plasma transport within that region. Looking at the integrated plasma flux (green and black curves), it is seen that the E-field peak is connected to a large plasma transport, in comparison to the surrounding BPS region. However, the E-field peaks cause a plasma flux in the opposite direction (anti-sunward) of the background plasma flow (sunward).

Figure 2 shows a case where the E-field peak related flux only has a negligible contribution to the entire plasma flux within the plotted region. Also this event appears at the highlatitude part of the dusk oval in the Southern Hemisphere, this time within a region of rather patchy particle distribu- tion during a SMC-like event with only moderate geomagnetic activity. Due to a data gap, the polar cap boundary is not seen on this plot. However, from overview plots it can be estimated that the oval boundary appears just poleward of plotted region. The E-field shows a bipolar structure, with a wide, but low peak in poleward, and a smaller, but very high peak in equatorward direction. The largest E-fields cause a strong plasma flux in anti-sunward (eastward) direction. Again, the flow directions are in opposite direction. The surrounding plasma flows in the sunward direction. Looking at the integrated flux curves, it is seen that the rapid flow associated with the E-field peak is negligible in comparison to the surrounding plasma flow. In this example, the E-field peak appears in a region with a rather slowly changing density profile. Thus, the density has no important influence on the shape of the rapid plasma flux associated with the intense E-field peak.

Figures 1 and 2 are typical examples of the two scenarios during which the plasma convection is not enhanced by intense E-field events: 1 . a strong E-field peak may give rise to a plasma flow in the opposite direction to the average plasma convection. 2. The E-field peak is too narrow to make a considerable contribution to the average convection. 
Table 2. Contribution of the E-peak related flux to the average background flux.

\begin{tabular}{lccccc}
\hline E-peak flux direction compared to backrgound flux & \multicolumn{2}{c}{ same direction } & \multicolumn{2}{c}{ opposite direction } \\
E-peak contribution to background flux & large & small & large & small \\
\hline Substorm expansion events & 5 & 6 & 2 & 0 \\
Small substorm/SMC events & 1 & 2 & 1 & 5 \\
Substorm recovery events & 5 & 1 & 0 & 4 \\
All events & 11 & 9 & 3 & 9 \\
\hline
\end{tabular}

4.5 The contribution of intense E-field events to the background plasma flow

In Table 2 the direction and relative importance of strong Efield peaks for the plasma convection is examined for the entire dataset. For Table 2, plasma flux plots are produced, showing the E-field orthogonal component of the plasma flux. For this, a minimum variance analysis of the E-field has been done. The coordinate system is rotated so that the flux component orthogonal to the strongest E-field gradient is shown. The number of events for which the rapid flows associated with the strong E-field peak are in the same direction as the surrounding plasma flow are given in columns 2 and 3. Those E-field peaks connected to flows in opposite direction as the surrounding plasma flow are shown in columns 4 and 5. For each group, it is then decided whether the rapid flow makes a large (columns 2 and 4) or small contribution (columns 3 and 5) to the average plasma transport of the surrounding plasma. We define a "large" or "small" contribution as one of more or less than $25 \%$ of the total flux within over an approximately 3-4 degrees broad region of the poleward oval, that is passed by Cluster within $30 \mathrm{~min}$. To see whether there are any systematic differences for different substorm phases, the dataset is split into the same substorm categories as in Fig. 4. Note, that nearly all (12 of 14) E-field peaks of Table 2 with a large flux contribution, are responsible for more than $60 \%$ of the average plasma flux, i.e. they make an important contribution to the general plasma transport. Nearly all (14 of 17) E-field peaks with a small contribution, change the plasma transport with less than $10 \%$, i.e. the influence of intense E-fields on the plasma flux are negligible in those cases.

Looking at the sum of all events (last row in Table 2) it is found that about two third of all strong E-field peaks are connected to rapid flows that are in the same direction as the surrounding plasma flow. However, only one third of the Efield peaks are connected to an enhanced plasma transport that contributes considerably to the general plasma convection. Comparing the different substorm phases in Table 2 (and excluding the two quiet time events where one makes an important, the other one a negligible contribution to the surrounding flux), we find that $41 \%$ substorm expansion and recovery E-field peak events are important and in the same direction as the background plasma flow, while only $11 \%$ small substorm/SMC events matter. These results indicate that during magnetically disturbed times (maximum $A_{E}$ values above $500 \mathrm{nT}$ ) the plasma transport connected to E-field peaks becomes more often important than during less disturbed times. Still, even during large substorms, most E-field peaks have a negligible influence, as the E-field peak width and connected plasma flux are much too small.

\section{Discussion}

In this work, intense E-field events (500-1000 mV/m) are examined with respect to their location within the oval, their appearance within the substorm cycle, and their contribution to the general plasma transport in the surrounding plasma. As both converging and diverging intense E-field structures contribute to rapid plasma flows, this study is not limited to E-field structures associated with discrete arcs, but also covers E-field events connected to return currents. The latter are often associated with the occurrence of black auroral structures (Karlsson and Marklund, 1996). Johansson et al. (2007) observed, that intense E-field structures connected to primary and return currents have similar characteristics. Thus, we do not separate between converging (associated with discrete arcs) and diverging (connected to return currents) E-field structures when discussing the results.

\subsection{The spatial distribution of intense E-field events}

In the large statistical study by Johansson et al. (2007), covering all intense E-field events above $150 \mathrm{mV} / \mathrm{m}$ between 2001 and 2003 , only $13 \%$ of all detected E-field peaks have magnitudes above $500 \mathrm{mV} / \mathrm{m}$. The low number of strong E-field peaks has its reason in the high-latitude orbit of the Cluster satellites. With an apogee of $4 R_{E}$ a good data coverage of the region $4-7 R_{E}$ above the Earth exists mainly poleward of 74 CGLat (Johansson et al., 2005). Thus, E-field peaks connected to discrete arcs near the equatorward oval boundary around $60^{\circ}$ CGLat (such as growth phase arcs) are missed (Gérard et al., 2004). On the other hand, the strongest Efield events appear mainly at lower latitudes (Johansson et al., 2005). This explains why so few events are found and why most of the intense E-field peaks events in the nightside oval appear within a limited latitudinal range between $67.8^{\circ}$ and $75^{\circ}$ CGLat. 
Looking at the longitudinal distribution of the intense Efield events, Fig. 3 shows a maximum occurrence in the premidnight region, and a complete lack of events at dawn (the lack of intense E-field events near noon is due to the removal of events showing cusp signatures). This distribution is very similar to the distribution found for high-energetic electron acceleration events that are associated with discrete arcs (Newell et al., 1996b), and to the distribution of intense E-field events connected to return currents and black aurora (Karlsson and Marklund, 1996). The good agreement between Fig. 3 and the results of the much larger statistical studies by Newell et al. (1996b) and Karlsson and Marklund (1996) lets us believe that despite the limited number of events, our dataset is representative and general conclusions can be drawn regarding the role of very intense E-field events for the global plasma convection.

\subsection{Connection to different substorm phases}

As can be expected from an increasing occurrence frequency of discrete auroral arcs between weak and moderate geomagnetic activity (Johansson et al., 2005; Hamrin et al., 2005), the intense E-field events of our dataset appear rarely during quiet times. Our results indicate that this holds also for the diverging E-field structures, connected to the return current region. Figure 4 shows that the spatial distribution of the intense E-field events changes considerably with substorm phase. The shift of the E-field peak distribution from low latitudes along the nightside during substorm expansion to higher latitudes in the afternoon-to-noon oval sector during recovery probably reflects the westward and poleward expansion of the active oval region with its bright auroral displays during the course of a typical substorm (Akasofu, 1994).

The most striking result of Figs. 3 and 4 is that over half of the intense E-field events are embedded within a region of anti-sunward flow. The flow direction depends strongly on the substorm phase (Fig. 4). The sunward flow direction in the poleward oval region appearing in most expansion phase events is expected. It is generally believed that strong sunward plasma flow on auroral field lines during substorm expansion helps to remove additional magnetic flux that has been built up in the growth phase (Baker et al., 1995). As shown in Table 1, nearly all expansion phase events appear after at least one hour of predominantly southward IMF conditions. During such conditions, a clear 2-cell convection pattern appears (Weimer, 1995) and the convection reversal boundary overlaps quite well with the oval boundary (Sotirelis et al., 2005). The sharp particle cutoff at the polar cap boundary, that is observed in most expansion phase and peak substorm cases of our dataset, is a further indication that oval and convection reversal boundaries coincide, i.e. sunward plasma flow appears on entire oval width. As shown by Newell et al. (1996a), such a sharp particle cutoff is typical for the expansion phase.
The anti-sunward plasma transport, observed during nearly all recovery and the two quiet time events, is more surprising. Table 1 reveals that in most of these cases, northward IMF conditions prevail during the hour before the E-field peak occurs. The reason why most of the intense E-field events appear during northward IMF recoveries is, that during such IMF conditions the poleward oval region remains highly active throughout the recovery phase (Kullen and Karlsson, 2004), eventually developing into a (often duskwardly displaced) double-oval (Elphinstone et al., 1995). Our observations are also in agreement with Peria et al. (2001) who reported that only the poleward part of a double oval is connected to electrostatic electron acceleration. The observation of anti-sunward flow on dayside highlatitude regions during substorm recovery strengthens an idea put forward by Elphinstone et al. (1995) that the nightside LLBL may be part of the activated tail region during substorm recovery and/or northward IMF. Newell and Meng (1992) showed that the outer LLBL, containing anti-sunward plasma flow, thickens during such IMF conditions. As discussed above, there exist several reports of anti-sunward flow on auroral field lines during northward IMF: on the highlatitude part of a tear-drop shaped oval (Murphree et al., 1982), on the nightside part of transpolar arcs (Nielsen et al., 1990; Liou et al., 2005; Eriksson et al., 2005), and up to one degree latitude equatorward from the nightside oval boundary (Sotirelis et al., 2005). In nearly all of these reports, the LLBL is suggested as the source region of the anti-sunward flow regime.

5.3 The contribution of intense E-field events to the background plasma flow

The relative contribution of the plasma transport connected to the large E-field peaks as compared to the background plasma flow, is summarized in Table 2. The results are rather ambiguous: The plasma flux connected to the intense Efield events is in a majority of cases in the same direction as the background flow. However, only in one third of the events, the plasma transport connected to the strong E-field peak contributes considerably to the general plasma flux. To be able to interpret the results it is necessary to look at the correlations between density gradients, the shape of intense E-field events, their magnitude and width.

A perfectly bipolar E-field structure in a homogenous plasma would be associated with an equal but oppositely directed amount of plasma flux on both sides of a discrete arc. Thus, the net plasma transport would be zero. Observations show that most of the time, neither density nor E-field shape correspond to this idealized picture. In only 5 of the 32 cases of our dataset the oppositely directed plasma fluxes (nearly) cancel each other. In the large statistical study by Johansson et al. (2006), covering all E-field peaks above $150 \mathrm{mV} / \mathrm{m}$, it is shown that nearly all intense E-field events appear at plasma boundaries within the BPS. Assuming a close connection 
between plasma regions above the ionosphere and their magnetospheric source regions, this is in agreement with the widely accepted theory that FACs connected to discrete arcs are caused by shear flows along plasma boundaries within the magnetosphere. Even more important for the unequal amount of plasma flux on the different sides of discrete arcs is the non-bipolar shape of the intense E-field structure. Johansson et al. (2007) showed that $75 \%$ of the intense E-field peaks have a monopolar shape. A case by case inspection of our dataset reveals that, in contrast to the example shown in Fig. 1, for most events the flux curve is extremely similar to the E-field curve inside the BPS. This means that the density has only a minor influence on the total flux amount on both sides of the peak.

Although in nearly all cases the intense E-field leads to a net plasma transport, the contribution to the surrounding plasma flux is often negligible (Table 2). As can be easily seen from manual inspection of the E-field curves of the entire dataset, the reason for the low number of events with an important contribution to the background plasma flux is the inverse relationship between E-field scale-size (defined as full-width half-maximum of the E-field peak) and magnitude. Such a relationship has been previously reported from Freja for the return current region (Karlsson and Marklund, 1996) and Cluster observations for both primary and return current regions (Johansson et al., 2005, 2007). Karlsson and Marklund (1996) found that the potential variation across the E-field structure has the same order of magnitude for all events and is independent on the E-field peak scale-size. Johansson et al. (2007) get similar results for monopolar events when disregarding those scale-size ranges with very large error bars (not shown in their paper is that the same relation appears when all bipolar and monopolar events are merged into one group). Even for thin field-aligned current sheets connected to discrete arcs an inverse relationship between FAC width and FAC intensity has been found (Johansson et al., 2007; Stasiewicz and Potemra, 1998). The results from these very different studies point all in the same direction: large E-field peaks cannot get arbitrarily broad, thus, the plasma convection cannot be arbitrarily much enhanced with help of a single discrete auroral arc or return current acceleration structure. So far, no consistent theory has been presented that explains the anti-correlation of E-field peak width and height. We only know that the E-peak shape is likely to be influenced by both the state of the ionosphere and the state of the magnetosphere. Increasing geomagnetic activity is connected to an increased E-field peak (Johansson et al., 2007), whereas the ionospheric conductivity has the opposite effect on E-field peaks. Their magnitude (Karlsson and Marklund, 1996), and width decreases with increasing conductivity (Johansson et al., 2007).

The results of this study show that, in general, intense Efield peaks do not contribute considerably to the total plasma transport within the BPS, unless there would be many parallel sheets of discrete arcs or black auroral arcs. A filamenta- tion of plasma boundaries with many steep density gradients resulting in many thin FACs would not only be connected to an enhanced energy and pressure release (as suggested by Haerendel, 2000), but also lead to a strongly enhanced net plasma transport due to the contribution of many plasma transport channels along discrete arcs. As pointed out by Haerendel (2000), the occurrence of multiple discrete arcs should be especially important during substorm expansion, where the need for plasma transport towards the dayside is much enhanced. It is questionable whether this is the case. In our dataset (within the studied 30-min passage through the BPS) typically 1 to $5 \mathrm{E}$-field peaks above $500 \mathrm{mV} / \mathrm{m}$ appear. The average number of strong E-field peaks during expansion/peak substorm, recovery/quiet time, and small substorm/SMC is 3.1, 2.3, and 2.1 (disregarding one SMC case with 16 peaks), respectively. However, only one quarter of the (in our study so far neglected) secondary E-field peaks make an important contribution to the surrounding plasma flux. Although there is a tendency that more of the very intense E-field peaks occur during large substorms, and that more of these make an important contribution, still, in half of events their contribution is negligible. This is in agreement with the statistical results of Johansson et al. (2005) and Hamrin et al. (2005). Johansson et al. (2005) show a similar correlation for intense E-field peaks. While there is a weak increase in the occurrence frequency of E-field peaks up to a level of $K_{p}=6$, the occurrence frequency does not rise further between strong and very strong activity $\left(6<K_{p}<9\right)$. Hamrin et al. (2005) reported that the occurrence probability of diffuse aurora rises much more with increasing $K_{p}$ values than the occurrence probability of discrete arcs. The enhanced plasma and energy release during very strong substorms is apparently not (only) regulated by an increased number of discrete arcs.

Future studies should use datasets that cover the entire cross-section of the auroral oval, including the oval of discrete arcs and the more equatorward located region of diffuse aurora. Only then the contribution of discrete arcs (and black aurora) to the entire magnetospheric plasma flow can be determined. As mentioned above, due to Clusters highlatitude orbit, a systematic examination of the equatorward oval region is not possible in the present study. However, some events from our list include even a small part of the CPS. From what can be seen in these data (e.g. Fig. 2, 19:5320:00 UT), the plasma flux within the CPS is much higher than in the entire BPS due to the very high density in this region (Newell et al., 1996b). Even small E-field values lead to a large amount of plasma flux in the CPS. It is highly probable that the main part of the magnetospheric plasma transport appears within the dense CPS near the equatorial plane and that the contribution of the entire BPS to the net plasma flux is negligible, even in those cases where an E-field peak makes an important contribution to the plasma flow within the surrounding BPS. 
To summarize: although the decoupling between ionosphere and magnetosphere at intense E-field peaks leads locally to extremely rapid plasma flows, it covers in most of the cases such a thin region close to the arc (or its return current region) that it has no effect on the large-scale plasma convection. Too few particles are transported with help of these rapid flows. Only during large substorms discrete arcs (and black aurora) may become important for the plasma transport within the BPS. The probability that arcs contribute much to the plasma transport rises during such conditions to over $40 \%$ (Table 2). Further investigations would be necessary to find out about their relative importance when including even the flux contribution from the CPS. We conclude: In general, intense high-altitude E-field peaks above the ionosphere cannot be regarded as the major driver of plasma convection. As the decoupling of the magnetosphere from the frictional ionosphere has most of the time only a local effect, it can be neglected when studying the global convection. Our results confirm the often used assumption that the ionospheric convection pattern is a good approximation for the global magnetospheric plasma flow.

\section{Summary and conclusions}

In this paper, the role of the plasma transport along discrete auroral arcs for the large-scale plasma convection is investigated. As not only converging E-field structures (primary currents connected to auroral arcs) but also diverging Efield structures (return currents) are connected to high plasma flows, we include also the latter ones in our study. 32 intense E-field peaks above $500 \mathrm{mV} / \mathrm{m}$ (when mapped to the ionosphere) with clear monopolar or bipolar structures have been identified in Cluster data, for which also density measurements are available. Due to Cluster's orbit all occur at high latitudes, in the poleward part of the boundary plasma sheet between polar cap and central plasma sheet. For each event, the particle flux within the poleward part of the boundary plasma sheet has been calculated and compared to the direction and strength of the net plasma transport related to the strong E-field peak.

- In nearly all cases the intense E-field structures are connected to a net plasma transport along the arc. This is caused in most cases by an asymmetric (near monopolar) structure of the E-field peak which appears typically at a density boundaries.

- Nearly all intense E-field peak events appear during active times.

- During substorm expansion and maximum phase, the average plasma transport within the boundary region is for most cases in sunward direction. Most intense Efield events appear near midnight.
- During substorm recovery the average plasma transport is in anti-sunward direction. Most events appear on high latitudes away from the nightside.

- For two third of the events, the E-field peak related plasma flux is in the same direction as the background flow within the boundary region.

- In only one third of the cases the net flux connected to the E-field peak gives a major contribution to the background flow. Nearly all of these appear during larger substorms. As most intense E-field peaks have an extremely narrow structure, their relative contribution to the general plasma flux is limited.

These results indicate that, although most strong E-field structures contribute to the plasma transport in the direction of the general plasma flow, intense high-altitude E-field cannot be regarded in general as major driver of plasma convection. This means, in most cases the plasma flow measured in the frictional ionosphere is a good approximation for the global plasma convection in the magnetosphere, even in those regions that are decoupled from the ionosphere due to strong, field-parallel E-fields.

Acknowledgements. The authors thank the National Space Science Data Center for providing IMF data through the GSFC/SPDF OMNIWeb interface. We also would like to acknowledge the WDC-C2 Kyoto $A_{E}$ index service, the $A_{E}$ stations, and the persons who derive the index for access to preliminary $A_{E}$ index data.

Topical Editor M. Pinnock thanks two anonymous referees for their help in evaluating this paper.

\section{References}

Akasofu, S.-I.: The development of the auroral substorm, Planet. Space Sci., 12, 273-282, 1964.

Baker D. N., Klimas, A. J., and Vassiliadis, D. V.: Energy transfer between the solar wind and the magnetosphere-ionosphere system, J. Geomagn. Geoelectr., 47, 1171-1182, 1995.

Burch, J. L., Reiff, P. H., Menietti, J. D., Heelis, R. A., Hanson, W. B., Shawhan, S. D., Shelley, E. G., Sugiura, M., Weimer, D. R., and Winningham, J. D.: IMF By-dependent plasma flow and Birkeland currents in the dayside magnetosphere: 1. Dynamics Explorer observations, J. Geophys. Res., 90, 1577-1593, 1985.

Burke, W. I., Machuzak, J. S., Maynard, N. C., Basinska, E. M., Erickson, G. M., Hoffman, R. A., Slavin, J. A., and Hanson, W. B.: Auroral ionospheric signatures of the plasma sheet boundary layer in the evening sector, J. Geophys. Res., 99, 2489-2499, 1994.

Carlqvist, P. and Boström, R.: Space-charge regions above the aurora, J. Geophys. Res., 75, 7140-7146, 1970.

Dungey, J. W.: Interplanetary magnetic field and the auroral zones, Phys. Rev. Lett., 6, 47-49, 1961.

Elphinstone, R. D., Jankowska, K., Murphree, J. S., and Cogger, L. L.: The configuration of the auroral distribution for interplanetary magnetic field Bz northward: 1. IMF Bx and By dependencies as observed by the Viking satellite, J. Geophys. Res., 95, 5791-5793, 1990. 
Elphinstone, R. D., Murphree, J. S., Hearn, D. J., Cogger, L. L., Sandahl, I., Newell, P. T., Klumpar, D. M., Ohtani, S. Sauvaud, J. A., Potemra, T. A., Mursula, K., Wright, A., and Shapshak, M.: The double oval UV auroral distribution, 1. Implications for the mapping of auroral arcs, J. Geophys. Res., 100, 12 075-12 092, 1995.

Engwall, E., Eriksson, A. I., and Forest, J.: Wake formation behind positively charged spacecraft in flowing tenuous plasmas, Phys. Plasmas, 13, 062904, doi:10.1063/1.2199207, 2006.

Eriksson, S., Baker, J. B. H., Petrinec, S. M., Wang, H., Rich, F. J., Kuznetsova, M., Dunlop, M. W., Reme, H., Greenwald, R. A., Frey, H. U., Luhr, H., Ergun, R. E., Balogh, A., and Carlson, C. W.: On the generation of enhanced sunward convection and transpolar aurora in the high-latitude ionosphere by magnetic merging, J. Geophys. Res., 110, A11218, doi:10.1029/2005JA011149, 2005.

Eriksson, A. I., André, M., Klecker, B., Laakso, H., Lindqvist, P.-A., Mozer, F., Paschmann, G., Pedersen, A., Quinn, J., Torbert, R., Torkar, K., and Vaith, H.: Electric field measurements on Cluster: comparing the double-probe and electron drift techniques, Ann. Geophys., 24, 275-289, 2006, http://www.ann-geophys.net/24/275/2006/.

Escoubet, C. P., Pedersen, A., Schmidt, R., and Lindqvist, P.-A.: Density in the magnetosphere inferred from ISEE 1 spacecraft potential, J. Geophys. Res., 102, 17 595-17 610, 1997.

Feldstein, Y. I., Gromova, L. I., Woch, J., Sandahl, I., Blomberg, L., Marklund, G., and Meng, C.-I.: Structure of the auroral precipitation region in the dawn sector: relationship to convection reversal boundaries and field-aligned currents, Ann Geophys., 19, 495-519, 2001.

Figueiredo, S., Marklund, G., Karlsson, T., Johansson, T., Ebihara, Y., Ejiri, M., Ivchenko, N., Lindqvist, P.-A., Nilsson, H., and Fazakerley, A.: Temporal and spatial evolution of discrete auroral arcs as seen by Cluster, Ann. Geophys., 23, 2531-2557, 2005, http://www.ann-geophys.net/23/2531/2005/.

Gérard, J.-C., Hubert, B., Gérard, A., Meurant, M., and Mende, S. B.: Solar wind control of auroral substorm onset locations observed with the IMAGE-FUV imagers, J. Geophys. Res., 109, A03208, doi:10.1029/2003JA010 129, 2004.

Gustavsson, G., Boström, R., , Holback, B., Holmgren, G., Lundgren, A., Stasiewicz, K., Åhlen, L., Mozer, F., Pankow, D., Harvey, P., Berg, P., Ulrich, R., Pedersen, A., Schmidt, R., Butler, A. Fransen, A., Klinge, D., Thomsen, M., Fälthammar, C.-G., Lindqvist, P.-A., Christenson, S., Holtet, J., Lybekk, B., Stein, T., Tanskanen, P., Lappalainen, K., and Wygant, J.: The electric field and wave experiment for the Cluster mission, Space Sci. Rev., 79(1-2), 137-156, 1997.

Haerendel, G.: Disruption, ballooning or auroral avalanche - on the cause of substorms, Proc. ICS-1, European Space Agency, SP335, 417-420, 1992.

Haerendel, G.: Outstanding Issues in understanding the dynamics of the inner plasma sheet and ring current during storms and substorms, Adv. Space Res., 25, 2379-2388, 2000.

Haerendel, G.: Conditions for auroral particle acceleration, Adv. Space Res., 30, 1763-1774, 2002.

Hamrin, M., Norqvist, P., Rönnmark, K., and Fellgård, D.: The importance of solar illumination for discrete and diffuse aurora, Ann. Geophys., 23, 3481-3486, 2005, http://www.ann-geophys.net/23/3481/2005/.
Hsu, T. S. and McPherron, R. L.: Occurrence frequencies of IMF triggered and nontriggered substorms, J. Geophys. Res., 108, 1307, doi:10.1029/2002JA009442, 2003.

Johansson, T., Figueiredo, S., Karlsson, T., Marklund, G., Fazakerely, A., Buchert, S., Lindqvist, P.-A., and Nilsson, H.: Intense high-altitude auroral electric fields - temporal and spatial characteristics, Ann. Geophys., 22, 2485-2495, 2004,

http://www.ann-geophys.net/22/2485/2004/.

Johansson,T., Karlsson, T., Marklund, G., Figueiredo, S., Lindqvist, P.-A., and Buchert, S.: A statistical study of intense electric fields at 4-7 Re geocentric distance using Cluster, Ann. Geophys., 23, 2579-2588, 2005, http://www.ann-geophys.net/23/2579/2005/.

Johansson, T., Marklund, G., Karlsson, T., Lileo, S., Lindqvist, P.A., Marchaudon, A., Nilsson, H., and Fazakerley, A.: On the profile of intense high-altitude auroral electric fields at magnetospheric boundaries, Ann. Geophys., 24, 1713-1723, 2006, http://www.ann-geophys.net/24/1713/2006/.

Johansson, T., Marklund, G., Karlsson, T., Lileo, S., Lindqvist, P.A., Nilsson, H., and Buchert, S.: Scale sizes of intense auroral electric fields observed by Cluster, Ann. Geophys., 25, 24132425, 2007, http://www.ann-geophys.net/25/2413/2007/.

Johnstone, A., Alsop, C., Burge, S., Carter, P. J., Coates, A. J., Coker, A. J., Fazakerely, A. N., Grande, M. Gowen, R. A., Gurgiolo, C., Hancock, B. K., Narheim, B., Preece, A., Sheather, P. H., Winningham, J., and Woodliffe, R. D.: PEACE: A plasma electron and current experiment, Space Sci. Rev., 19(1-2), 351398, 1997.

Karlsson, T. and Marklund, G. T.: A statistical study of intense lowaltitude electric fields observed by Freja, Geophys. Res. Lett., 23, 1005-1008, 1996.

Kamide, Y., Sun, W., and Akasofu, S.-I.: The average ionospheric electrodynamics for the different substorm phases, J. Geophys. Res., 101, 99-109, 1996.

Keiling, A., Wygant, J., Cattell, C., Johnson, M., Temerin, M., Mozer, F., Kletzing, C., Scudder, J., and Russell, C.: Properties of large electric fields in the plasma sheet at 4-7 Re measured with Polar, J. Geophys. Res., 106, 5779-5798, 2001.

Knight, S.: Parallel electric field, Planet. Space Sci., 21, 741-750, 1973.

Kullen, A. and Karlsson, T.: On the relation between solar wind, pseudobreakups, and substorms, J. Geophys. Res., 109, A12218, doi:10.1029/2004JA010488, 2004.

Liou, K., Ruohoniemi, J. M., Newell, P. T., Greenwald, R., Meng, C. I., and Hairston, M. R.: Observations of ionospheric plasma flows within theta auroras, J. Geophys. Res., 110, A03303, doi:10.1029/2004JA010735, 2005.

Lyons, L. R., Nagai, T., Blanchard, G. T., Samson, J. C., Yamamoto, T., Mukai, T., Nishida, A., and Kokubun, S.: Association between Geotail plasma flows and auroral poleward boundary intensifications observed by CANOPUS photometers, J. Geophys. Res., 104, 4485-4500, 1999.

Makita, K., Meng, C.-I., and Akasofu, S. I.: Latitudinal electronprecipitation patterns during large and small IMF magnitudes for northward IMF conditions, J. Geophys. Res., 93, 97-104, 1988.

Marklund, G. T.: Auroral arc classification scheme based on the observed arc-associated electric field pattern, Planet. Space Sci. 32, 193-211, 1984.

Marklund, G. T., Karlsson, T., Figueiredo, S., Johansson, T., Lindqvist, P.-A., André, M., Buchert, S., Kistler, L. M., and 
Fazakerley, A.: Characteristics of quasi-static potential structures observed in the auroral return current region by Cluster, Nonlin. Processes Geophys., 11, 709-720, 2004, http://www.nonlin-processes-geophys.net/11/709/2004/.

Marklund G., Johansson, T., Lileo, S., and Karlsson, T.: Cluster observations of an auroral potential and associated field-aligned current reconfiguration during thinning of the plasma sheet boundary layer, J. Geophys. Res., 112, A01208, doi:10.1029/2006JA011804, 2007.

McPherron, R. L.: Substorm related changes in the geomagnetic tail: the growth phase, Planet. Space Sci., 20, 1521-1539, 1972.

Mozer, F. S., Catell, C. A., Hudson, M. K., Lysak, R. L., Temerin, M., and Torbert, R. B.: Satellite measurements and theories of low-altitude auroral particle acceleration, Space Sci. Rev., 27, 155-213, 1980.

Moore, T. E., Chappell, C. R., Chandler, M. O., Craven, P. D., Giles, B. L., Pollock, C. J., Burch, J. L., Young, D. T., Waite, J. H., Nordholt, J. E., Thomsen, M. F., McComas D. J., Berthelier, J. J., Williamson, W. S., Robson, R., and Mozer, F. S.: High-altitude observations of the polar wind, Science, 277, 349-351, 1997.

Murphree, J. S., Anger, C. D., and Cogger, L. L.: The instantaneous relationship between polar cap and oval auroras at times of northward interplanetary magnetic field, Can. J. Phys., 60, 349-356, 1982.

Newell, P. T. and Meng, C.-I.: Mapping the dayside ionosphere to the magnetosphere according to particle-precipitation characteristics, J. Geophys. Res., 19, 609-612, 1992.

Newell, P. T., Burke, W. J., Sanchez, E. R., Meng, C.-I., Greenspan, M. E., and Clauer, C. R: The low-latitude boundary-layer and the boundary plasma sheet at low altitude - prenoon precipitation regions and convection reversal boundaries, J. Geophys. Res., 96, 21 013-21 023, 1991.

Newell, P. T., Feldstein, Y. I., Galperin, Y. I., and Meng, C.-I.: Morphology of nightside precipitation, J. Geophys. Res., 101, 10737-10748, 1996a.

Newell, P. T., Meng, C.-I., and Lyons, K. M.: Suppression of discrete aurorae by sunlight, Nature, 381, 766-767, $1996 \mathrm{~b}$.

Newell, P. T., Meng, C.-I., and Wing, S: Relation to solar activity of intense aurorae in sunlight and darkness, Nature, 393, 342-344, 1998.

Nielsen, E., Craven, J. D., Frank, L. A., and Heelis, R. A.: Ionospheric flows associated with a transpolar arc, J. Geophys. Res., 95, 21 169-21 178, 1990.

Pedersen, A., Décréau, P., Escoubet, C.-P., Gustafsson, G., Laakso, H., Lindqvist, P.-A., Lybekk, B., Masson, A., Mozer, F., and Vaivads, A.: Four-point high time resolution information on electron densities by the electric field experiments (EFW) on Cluster, Ann. Geophys., 19, 1483-1489, 2001, http://www.ann-geophys.net/19/1483/2001/.

Pedersen, A., Lybekk, B., André, M., Eriksson, A., Lindqvist, P.A., Mozer, F., Décréau, P. M. E., Masson, A., Laakso, H., Reme, H., Sauvaud, J.-A., Fazakerley, A., Svenes, K., Paschmann, G., Torkar, K., and Whipple, E.: Electron density estimations derived from spacecraft potential measurements on Cluster in tenuous plasma regions, J. Geophys. Res., 113, A07S33, doi:10.1029/2007JA012636, 2008.
Peria, W. J., Brittnacher, M. J., Parks, G. K., and Carlson, C. W.: Mircroscopic signatures of the bipartite auroral oval: FAST measurements, J. Geophys. Res., 106, 29 645-29 653, 2001.

Reme, H., Bosqued, J. M., Sauvaud, J. A., Cros, A., Dandouras, J., Aoustin, C., Bouyssou, J. Camus, T., Cuvilo, J., Martz, C., Medale, J. L., Perrier, H., Romefort, D., Rouzaud, J., D’Uston, C., Möbus, E., Crocker, K., Granoff, M., Kistler, L. M., Popecki, M., Hovestadt, D., Klecker, B., Paschmann, G., Scholer, M., Carlson, C. W., Curtis, D. W., Lin, R. P., Mcfadden, J. P., Formisano, V., Amata, E., Bavassano-Cattaneo, M. B., Baldetti, P., Belluci, G., Bruno, R., Chionchio, G., Lellis, A. D., Shelley, E. G., Ghielmetti, A. G., Lennartsson, W., Korth, A., Rosenbauer, H., Lundin, R., Olsen, S., Parks, G. K., Mccarthy, M., and Balsiger, H.: The Cluster ion spectrometry (CIS) experiment, Space Sci. Rev., 19(1-2), 303-350, 1997.

Schriver, D., Ashour-Abdalla, M., Strangeway, R., Richard, R., Kletzing, C., Dotan, Y., and Wygant, J.: FAST/Polar conjunction study of field-aligned auroral acceleration and corresponding magnetotail drivers, J. Geophys. Res., 108, A9COA21, 1-21, 2003.

Sergeev, V. A., Pellinen, R. J., and Pulkkinen, T. I.: Steady magnetospheric convection: A review of recent results, Space Sci. Rev., 75, 551-604, 1996.

Stasiewicz, K. and Potemra, T.: Multiscale current structures observed by Freja, J. Geophys. Res., 103, 4315-4325, 1998.

Sotirelis, T., Ruohoniemi, J. M., Barnes, R. J., Newell, P. T., Greenwald, R. A., Skura, J. P., and Meng, C.-I.: Comparison of SuperDARN radar boundaries with DMSP particle precipitation boundaries, J. Geophys. Res., 110, A06302, doi:10.1029/2004JA010732, 2005.

Torkar, K., Riedler, W., Escoubet, C. P., Fehringer, M., Schmidt, R., Grard, R. J. L., Arends, H., Rüdenauer, F., Steiger, W., Narheim, B. T., Svenes, K., Torbert, R., André, M., Fazakerley, A., Goldstein, R., Olsen, R. C., Pedersen, A., Whipple, E., and Zhao, H.: Active spacecraft potential control for Cluster - implementation and first results, Ann. Geophys., 19, 1289-1302, 2001, http://www.ann-geophys.net/19/1289/2001/.

Weimer, D. R.: Models of high-latitude electric potentials derived with a least error fit of spherical harmonic coefficients, J. Geophys. Res., 100, 19595-19607, 1995.

Weiss, L. A., Reiff, P. H., Hilmer, R. V., Winningham, J. D., and Lu, G.: Mapping the auroral oval into the magnetotail using dynamics explorer plasma data, J. Geomagn. Geoelectr., 44, 11211144, 1992.

Winningham, J. D. Yasuhara, F., Akasofu, S. I., and Heikkila, W. J.: Latitudinal morphology of $10-\mathrm{eV}$ to $10-\mathrm{keV}$ electron fluxes during magnetically quiet and disturbed times in 2100-0300 MLT sector, J. Geophys. Res., 80, 3148-3171, 1975.

Woch, J. and Lundin, R.: The low-latitude boundary-layer at midaltitudes - relation to large-scale Birkeland currents, Geophys. Res., Lett., 20, 979-982, 1993.

Yahnin, A. G., Sergeev, V. A., Gyozdeysky, B. B., and Vennerström, S.: Magnetospheric source region of discrete auroras inferred from their relationship with isotropy boundaries of energetic particles, Ann. Geophys., 15, 943-958, 1997, http://www.ann-geophys.net/15/943/1997/. 